\title{
VOLEIBOL SENTADO: DO CONHECIMENTO À INICIAÇÃO DA PRÁTICA
}

Camila Lopes Carvalho, Universidade Estadual de Campinas - UNICAMP, Campinas, São Paulo - Brasil

José Irineu Gorla, Universidade Estadual de Campinas - UNICAMP, Campinas, São Paulo-Brasil

Paulo Ferreira de Araújo, Universidade Estadual de Campinas - UNICAMP, Campinas, São Paulo-Brasil

\section{RESUMO}

As Paralimpíadas têm conquistado, a cada ano, maior espaço no cenário esportivo mundial.Dentre as modalidades paralímpicas destaca-se o voleibol sentado - um esporte,incluído oficialmente nestes Jogos em 1980, destinado às pessoas com deficiência física (amputações e LesAutres). O Brasil teve sua primeira participação paralímpica nesta modalidade apenas em Pequim, em 2008. Considerando essa prática recente, esta pesquisa tem por objetivo reunir materiais bibliográficos sobre o voleibol sentado propondo um método de iniciação à sua prática. Para isso foi realizada uma revisão bibliográfica utilizando dados impressos e eletrônicos da base de dados da Universidade Estadual de Campinas. Observa-se com essa pesquisa que, apesar da grande escassez literária sobre o tema, há semelhanças nos aspectos técnico-táticos entre o voleibol sentado e o convencional, possibilitado uma opção de trabalho aos profissionais de educação física. Espera-se, com esse trabalho, contribuir para a propagação do conhecimento a respeito do voleibol sentado, oferecendo subsídios para que o profissional de educação física possa explorá-lo e desenvolve-lo, tornando-o accessível e proporcionando mais uma opção de prática para as pessoas com deficiência.

Palavras-Chave: Voleibol sentado; Pessoa com deficiência; Esporte adaptado.

\section{SITTINGVOLLEYBALL: THE KNOWLEDGETOINITIATIONOFPRACTICE}

\section{SUMMARY}

The Paralimpíadas has won every year, more space in the sports world. Among the modalities highlight the Paralympic sitting volleyball-a sport officially included in these Gamesin 1980, for persons with physical disabilities (amputations and Les Autres). Brazil had its first Paralympic participation in this mode only in Beijing in 2008.Considering this recent practice, this research aims to gather bibliographic materials on the sitting volleyball proposing a method of initiation into their practice. For this we conducted a literature review using electronic and print data from the data base of the State University of Campinas. It is observed from this study that, despite the paucity literature on the subject, there are similarities in technical-tactical and sitting volleyball between conventional enabled an option for professionals working in physical education. It is hoped, with this work, contribute to the spread of knowledge about sitting volleyball, offering subsidies for 
the physical education teachers can explore and develop the sport, making it more accessible and providing an option for people to practice with disabilities.

Key-Words: Sitting volleyball; Persons with disabilities; Adapted sports.

\section{VOLEIBOL SENTADO: EL CONOCIMIENTO A LAINICIACIÓNDELA PRÁCTICA}

\section{RESUMEN}

Las Paralimpíadas han ganado, todos los años, más espacio en el mundo del deporte. Entre las modalidades de relieve la Paralímpico voleibol sentado- un deporte incluido oficialmente en os Juegos en 1980, para las personas con discapacidades físicas (amputaciones y les autres). Brasil tuvo su primera participación Paralímpicos de este modo sólo en Beijingen 2008.Teniendo en cuenta esta práctica reciente, esta investigación tiene como objetivo reunir material bibliográfico en el voleibol sentado proponiendo un método de iniciación en la práctica. Para ello se realizó una revisión de la literatura a partir de datos electrónicos e impresos de la base de datos de la Universidad Estatal de Campinas. Se observa en este estudio que, a pesar de la escasez literatura, hay similitudes en técnico-táctico y voleibol sentado entre convencional activar una opción para los profesionales que trabajan en la educación física. Se espera, contribuir a la difusión del conocimiento acerca de voleibol sentado, ofreciendo subsidios para los profesores de educación física pueden explorar y desarrollar el deporte, haciéndolo más accesible y proporciona una opción para las personas que practican con discapacidad.

Palabras-Clave: Voleibol sentado; Personas con discapacidad; Deporte adaptado. 


\section{INTRODUÇÃO}

A concretização do esporte destinado exclusivamente para pessoas com deficiência ocorreu em 1944, quando o médico Dr. Ludwing Guttmann passou a utilizá-lo para reabilitação de soldados lesionados durante a guerra e organizou os Jogos de Stoke Mandeville, em 1948, destinado á estes. Posteriormente, o esporte adaptado sofreu inúmeras evoluções quanto à organização, parâmetros técnicos esportivos, número de modalidades e participantes, transformando os Jogos de Stoke Mandeville nas atuais Paraolimpíadas. ${ }^{1}$

O Voleibol Sentado - um esporte adaptado para pessoas com deficiência física (pessoas com amputação ou lesautres) - surgiu em 1956 a partir da união do voleibol convencional com o Sitzball (jogo sentado no chão, sem rede, de origem alemã) e foi incluído nas Paraolimpíadas em 1980.² Com regras semelhantes as do voleibol convencional, as principais diferenças são o menor tamanho da quadra, aaltura mais baixa da rede, o deslocamento dos jogadores sentados e a permissão de bloqueiodo saque. ${ }^{3}$

Há grande escassez literária sobre o tema,com poucos trabalhos relevantes como os de Vute, ${ }^{4,5}$ Mustafins, ${ }^{6}$ Macedo $^{7}$ e Almeida. ${ }^{8}$ Dessa forma, o presente estudo busca estabelecer bases para a iniciação da prática do voleibol sentado por pessoas de quaisquer faixas etárias proporcionando difusão e massificação da prática desse esporte, realizando, para isso, revisão da literatura disponível (com fontes impressas e eletrônicas da base de dados impressa e online da Faculdade de Educação Física da Universidade Estadual de Campinas,acrescentados de livros, teses e artigos) como base para a elaboração de uma proposta de iniciação.

O baixo número de pessoas em condição de deficiência praticantes de esporte é oriundo, dentre vários outros fatores, da falta de oportunidade de vivências. Considerando o voleibol sentado como um esporte em pleno desenvolvimento com acréscimos constantes de adeptos a sua prática, é válida a busca de um método que facilite seu ensinoaprendizado de forma acessível, podendo ainda contribuir com a formação de futuros atletas. Ressalta-se ainda, nesse contexto, a facilidade em inserir a prática do voleibol paraolímpico em diferentes locais, como escolas, clubes ou outras instituições, por não exigir grandes recursos financeiros nem equipamentos especiais. ${ }^{7}$ 


\section{DESENVOLVIMENTO}

O esporte adaptado é um esporte pensado e organizado para ser vivenciado por uma população específica. ${ }^{9} \mathrm{O}$ exercício físico já era utilizado com finalidades terapêuticas desde, aproximadamente, 2.500 a.C., na China, porém os primeiros registros de prática esportiva oficial por pessoas com deficiência são de 1888, com a criação do Primeiro Clube Esportivo Para Surdo. Apesar dessa origem antiga, sua prática era escassa, sendo consolidada apenas a partir da Segunda Guerra Mundial, como forma de reabilitação física e psicossocial dos soldados lesionados. Dessa forma, em 1944,o médico Dr. Ludwing Guttmann, refugiado da Alemanha nazista, fundou na Inglaterra um centro de reabilitação no Hospital de Stoke Mandeville, utilizando o esporte como uma forma de reabilitação e, em 1948, organizou os Jogos de Mandeville, destinados a pessoas em cadeira de rodas. ${ }^{10}$

Concomitantemente, nos Estados Unidos, em 1946, Benjamin H. Lipton iniciou um programa esportivo para pessoas que se locomoviam por cadeira de rodas difundindo-o em todo o país junto com o professor Timothy Nugent. ${ }^{9}$

Ocorreu então, em 1950, o encontro entre o Dr. Guttmann e Lipton, culminando no desenvolvimento dos Jogos de Mandeville que, com a participação de cada vez um número maior de países e modalidades esportivas, obteve reconhecimento oficial pelo Comitê Olímpico Internacional, em 1956. Já em 1964, nos Jogos de Tóquio, adotou-se o termo de "Paraolimpíco" (possível união das palavras paraplegia e olímpico) e passou a ser realizado na mesma cidade das Olimpíadas a partir dos Jogos de Seul, em 1988, sendo essa realização conjunta obrigatória a partir de 2000. ${ }^{10}$ Já no ano de 2012, o termo "paraolímpico" foi substituído oficialmente, nos países de língua portuguesa por "paraolímpico".

No Brasil, a prática de esporte adaptado começou por uma iniciativa popular, quando Robson Sampaio de Almeida e Sérgio Serafim Del Grande, ambos com deficiência física, foram para os Estados Unidos para a realização de um programa de reabilitação, participando de vivências em esportes adaptados. Retornando ao Brasil, eles organizaram o Clube dos Paraplégicos em São Paulo e do Clube do Otimista no Rio de Janeiro, iniciando essa prática no país. Em seguida, o esporte adaptado adquiriu atenção política, após os anos 70, passando sequencialmente, por um processo de institucionalização no Brasil, com 
relevantes ações políticas na área como os Congressos Brasileiros do Esporte para Todos, o Projeto Integrado SEED/CENESP, o Plano Nacional de Ação Conjunta para Integração da Pessoa Deficiente, o Plano Plurianual e o Encontro Técnico de Avaliação Desportiva das Pessoas Portadoras de Deficiência. Paralelamente, foram surgindo organizações como Associação Nacional de Desporto para Deficientes (ANDE), a Associação Brasileira de Desportos em Cadeira de Rodas (ABRADECAR), a Associação Brasileira de Desportos para Amputados (ABDA), além do Comitê Paraolímpico Brasileiro (CPB). ${ }^{9}$

\section{Voleibol Sentado}

O voleibol sentado é um esporte paraolímpico destinado às pessoas impossibilitadas de praticar o voleibol convencional, estruturando-se aquele com pequenas modificações em relação a este. De acordo com Tajnik, ${ }^{11}$ esse esporte surgiu em 1.956 na Holanda, pela criação de T. Van Der Scheer e A. Albers, ao unirem o Sitzball (jogo alemão no qual os participantes ficavam sentados no chão, porém sem serem divididos por uma rede) com o voleibol convencional. Foi criado, dessa forma, pelo Comitê de Esportes da Holanda, o Voleibol Sentado.

Em 1976, o voleibol sentado teve participação como jogos de exibição nas Paraolimpíadas de Toronto, e em 1978, foi oficialmente aceito nas Paraolimpíadas pela Organização Internacional de Esportes para Deficientes (ISOD),participando, em 1980, pela primeira vez nos Jogos Paraolímpicos da Arnhem, nos Países Baixos. A partir de 1993, campeonatos mundiais tanto masculinos como femininos desta modalidade passaram a ser organizados.

Essa modalidade paralímpica permaneceu dividida em duas categorias, com disputas com participantes sentados ou em pé (utilizando próteses e equipamentos) até os Jogos Paraolímpicos de Sydnei, em 2000. A partir de 2004, nas Paraolimpíadas de Atenas, estabeleceu-se que sua disputa seria apenas na categoria sentado e incluiu, pela primeira vez, a participação de equipes femininas. ${ }^{12}$

No Brasil, sua história foi iniciada em 2002, quando o professor Ronaldo Gonçalves de Oliveira, organizou um torneio oficial em Mogi das Cruzes, São Paulo. No ano seguinte, foi criada a Associação Brasileira de Voleibol Paraolímpico (ABVP) e o país participou 
pela primeira vez dos Jogos Parapanamericanos, alcançando a conquista da segunda colocação nas modalidades feminina e masculina. No ano de 2008, o Brasil participou pela primeira vez das Paraolimpíadas, em Pequim, com uma equipe masculina de voleibol sentado, obtendo neste evento, a sexta colocação mundial.Atualmente o Voleibol Paraolímpico é organizado no Brasil pela Associação Brasileira de Voleibol Paraolímpico (ABVP) e internacionalmente pela World Organization Volleyball for the Disabled (WOVD) - Organização Mundial de Voleibol para Deficientes.

No âmbito competitivo, os esportes adaptados são regidos por sistemas de classificação com o objetivo de estabelecer competições as mais justas possíveis e de evitar a ocorrência de possíveis lesões. Denominada de classificação funcional,nesta avaliação do voleibol adaptado há uma combinação da avaliação médica com a análise das habilidades do atleta no esporte em questão.De acordo com o $\mathrm{CPB},{ }^{2}$ a classificação funcional divide os atletas do voleibol em amputados e lesautres.

As amputações são divididas em nove classes:

- Classe $\mathrm{A} 1$ = ambos os membros inferiores são amputados acima ou através da articulação do joelho (Duplo AK-Above Knee);

- Classe A2 = um dos membros inferiores é amputado acima ou através da articulação do joelho (AK Simples);

- Classe A3 = ambos os membros inferiores são amputados abaixo do joelho, mas acima ou através da articulação tálus-calcanear (Duplo BKBelow Knee);

- Classe A4 = um dos membros inferiores é amputado abaixo do joelho, mas acima ou através da articulação tálus-calcanear (BK Simples);

- Classe A5 = ambos os membros superiores são amputados acima ou através da articulação do cotovelo (Duplo AE-Above Elbow);

- Classe A6 = um dos membros superiores é amputado acima ou através da articulação do cotovelo (AE Simples);

- Classe $\mathrm{A} 7=$ ambos os membros inferiores são amputados abaixo do cotovelo, mas acima ou através da articulação pulso (Duplo BE-Below Elbow); 
- Classe $\mathrm{A} 8=$ um dos membros superiores é amputado abaixo do cotovelo, mas acima ou através da articulação do pulso (BE Simples);

- Classe A9 = atletas com amputações de membro superior e inferior.

Já os Lês Autres englobam os atletas que possuem outras dificuldades locomotoras que não as amputações, como indivíduos com lesão medular, sequelas de poliomielite, distrofia muscular, artrite reumatóide juvenil, esclerose múltipla e paralisia cerebral. Dentro desta categoria estão contidos ainda os atletas com incapacidade mínima, podendo ser, por exemplo, pessoas com amputação de dedos ou das mãos e de um dos pés. Além destes, pessoas que possuem membros superiores encurtados, paresia ou paralisia de membros superiores, luxação da coxa, alteração na articulação de membros inferiores ou superiores e severo déficit de circulação nos membros inferiores também são inclusos nesta categoria. ${ }^{13}$

As regras do voleibol sentado, estabelecidas pela World Organization Volleyball for the Disable (WOVD) são, em sua maioria, as mesmas do voleibol convencional, tendo apenas algumas modificações necessárias para a realização de um jogo adequado e organizado.

Neste jogo, duas equipes - cada uma composta por 12 jogadores, cada uma contendo o máximo de 2 jogadores classificados como incapacidade mínima; estando em quadra apenas 6 jogadores de cada time, sendo destes apenas um com incapacidade mínima colocam-se em uma quadra dividida ao meio por uma rede, cada equipe permanecendo apenas na sua metade da quadra. O objetivo é fazer com que a bola toque no chão no lado da quadra da equipe adversária para marcar o ponto, evitando que a bola caia na sua própria metade da quadra. Para isso, são permitidos apenas três toques na bola antes de passá-la para o lado adversário, além do toque no bloqueio, sendo que a mesma pessoa não pode tocá-la duas vezes consecutivamente. A disputa inicia-se através do saque, este realizado sempre pela equipe que marcou o ponto.

O jogo é composto por quatro sets de 25 pontos e um quinto set denominado detie-break de 15 pontos. Vence a equipe que ganhar a marcar quantidade de sets, atingindo primeiro os pontos determinados com uma diferença de pelo menos 2 pontos da equipe adversária, prorrogando-se o número final de pontos em caso de empate 24 x 24, no qual a competição finalizará apenas com 26 pontos, e assim consecutivamente. Torna-se vencedor a equipe que ganhar a maior quantidade de sets.

Conexões: revista da Faculdade de Educação Física da UNICAMP, Campinas, v. 11, n. 2, p. 97-126, abr./jun. 2013.103 ISSN: 1983-9030 
A quadra na qual é disputado o jogo deve medir $10 \mathrm{~m}$ x $6 \mathrm{~m}$, com cada lado medindo $6 \mathrm{~m}$ x 5m, como apresentado na Figura 1. A linha de ataque é desenhada a 2 metros da linha central, sob a qual se posiciona a rede, cujo tamanho é de $0,8 \mathrm{~m}$ x 6,5-7,0 m., e deve ser colocada a uma altura de $1,15 \mathrm{~m}$ para as equipes masculinas e 1,05 $\mathrm{m}$ para as femininas.

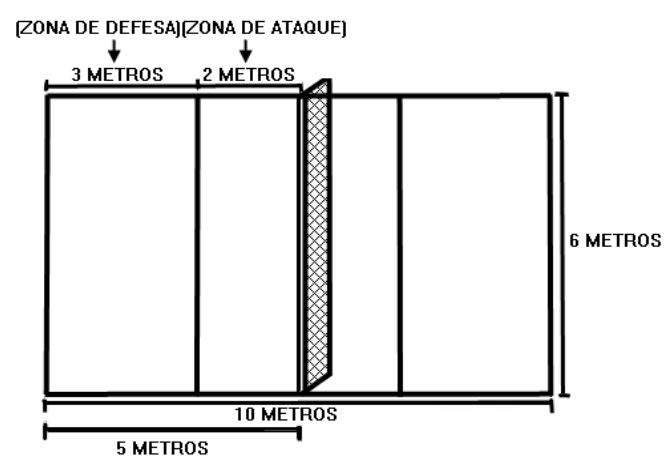

Figura 1: A quadra de voleibol sentado.

Os jogadores são permitidos de usarem calças compridas, sem a necessidade destas ou dos calções apresentarem o número do jogador, porém é proibido o uso de equipamentos ortopédicos ou de quaisquer materiais espessos sob os glúteos.

Os jogadores têm sua posição em quadra determinada pelo posicionamento de suas nádegas, recebendo como numeração da posição, de acordo com a WODV, ${ }^{3}$ o "1"(Jogador da linha de trás, na direita), “2”(Jogador da linha de frente, na direita), “3” (Jogador da linha de frente, no centro), "4" (Jogador da linha de frente, na esquerda), "5" (Jogador da linha de trás, na esquerda) ou "6" (Jogador da linha de trás, no centro).Cada jogador deve permanecer em sua posição até a realização do saque, após eles podem se deslocar por toda a quadra.Ganhando-se um ponto, a equipe realiza um rodízio, giro no sentido horário, e o jogador da posição número 1 sacará. 


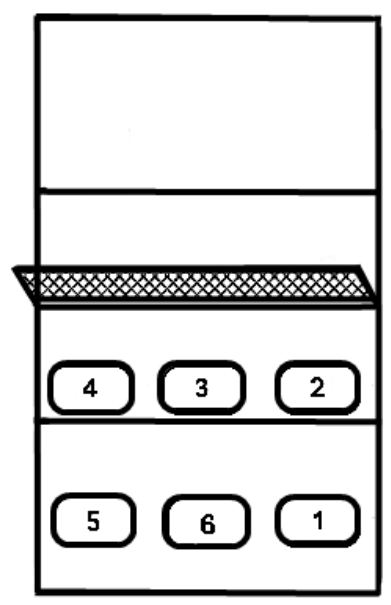

Figura 2: Posicionamento dos jogadores na quadra.

Durante o jogo, todos os jogadores devem manter contato com a quadra quando tocarem a bola com uma parte de seu corpo entre os ombros e as nádegas, sendo proibido que ele se erga, fique de pé ou dê passadas. Como o posicionamento é determinado pelas nádegas, os jogadores podem estender suas mãos, pernas e pés na zona de ataque (se ele estiver na linha de fundo realizando um golpe de ataque), na própria quadra ou na zona livre fora da quadra durante um saque (porém suas nádegas devem permanecer fora de quadra no caso do saque) e na quadra adversária, desde que isso não prejudique a outra equipe.

Numa das mais relevantes diferenças do convencional, o voleibol sentado permite o bloqueio do saque do adversário. Permite também uma pequena perda de contato do glúteo com a quadra quando a bola estiver mais alta que o topo da rede, exceto no saque, bloqueio e ataque. Os jogadores da linha de trás podem atacar desde que suas nádegas não ultrapassem a linha de ataque.

As faltas cometidas durante o jogo são punidas da mesma forma que no voleibol convencional. Apenas alguns novos critérios foram adotados, como o "Toque Apoiado"uma falta quando um jogador se apóia em outro jogador ou em alguma estrutura para tocar na bola dentro de sua área de jogo - e "Lifiting"- falta quando há perda de contato entre uma parte do corpo do jogador que se situe entre os ombros e as nádegas e o chão no momento em que este toca a bola. 


\section{Proposta de Treinamento Técnico-tático Para a Iniciação em Voleibol Sentado}

Para trabalhar com o esporte adaptado, torna-se necessária uma adequada capacitação dos profissionais de educação física, que devem estar atentos a vários fatores como o tipo de deficiência, as capacidades e peculiaridades de cada aluno, a garantia da segurança ao realizar as atividades físicas, além da compreensão dos resultados de exames médicos que são de suma importância antes da iniciação à prática e periodicamente a esta. Indispensável também é o conhecimento do profissional de educação física a respeito das medicações as quais os alunos possam estar ingerindo e a possível interação destas com a prática de atividades física, além do conhecimento sobre o esporte. ${ }^{4}$

Deve-se ressaltar que, em caso de treinamento esportivo, os participantes com deficiência devem ser tratados como atletas e não como atletas com deficiência, não fazendo distinções entre as formas de tratamento dos atletas com ou sem deficiência. É recomendado que os profissionais possuam conhecimento e compreensão sobre a importância da prática de esportes para as pessoas com deficiência e as possibilidades advindas com a prática esportiva para essas pessoas, além da legislação relacionada á inclusão, direitos e deveres da pessoa com deficiência. Além disso, aspectos como o entendimento de um desenvolvimento motor atípico e formas de auxílios às pessoas com deficiência devem ser conhecidas pelo profissional. ${ }^{14}$

O voleibol sentado faz parte dos chamados Jogos Desportivos Coletivos e, assim como os demais esportes, se trabalhado de forma adequada pode levar ao desenvolvimento não só técnico, mas também tático, cognitivo, social e afetivo dos participantes, além do desenvolvimento das habilidades específicas do esporte e das capacidades físicas e motoras. $^{15}$

O treinamento deste esporte, principalmente relacionado aos procedimentos técnicotáticos, é muito semelhante ao treinamento do voleibol convencional, sendo a principal diferença o trabalho do deslocamento que será feito sentado através do movimento pelo chão realizado por meio das mãos. Por isso, considerável tempo deve ser despendido com o trabalho dos aspectos da força muscular, da resistência física, do limiar da fadiga, equilíbrio e potência dos membros superiores. ${ }^{16}$ 
Para o início do ensino é aconselhável que o professor estimule primariamente a aquisição das habilidades básicas do voleibol adaptado, sem negligenciar as estratégias do esporte, pois o ensino de qualquer técnica deve conter informações que possibilitem o aluno a ter conhecimento sobre o porquê e para quê ele necessita aprender tal gesto, podendo escolher as atitudes mais adequadas de acordo com as situações momentâneas. ${ }^{17}$

A principal dificuldade das pessoas que iniciam a aprendizagem do voleibol é desenvolver uma rápida reação frente ao veloz deslocamento da bola, portanto, inicialmente é recomendado que sejam empregadas bolas de materiais diferentes do oficial, sendo maiores, mais leves, e até aquelas que tenham menor velocidade de deslocamento. As regras também devem ser ensinadas de forma mais simples e resumidas, aumentando-as e incorporando-as progressivamente ao jogo, assim como deve ser feito com as questões técnico-táticas, estimulando o desenvolvimento de uma visão global do jogo pelo aluno. ${ }^{4}$

Segundo as definições de Pirolo e Pirolo $^{18}$ sobre conceitos técnicos e táticos, no treinamento técnico estão inclusos os fundamentos - o toque, a manchete, o saque, a cortada, o bloqueio e o deslocamento. Já a tática pode ser realizada individualmente ou de forma coletiva, sendo que na tática individual compreende o saque, passe, levantamento e ataque; e na coletiva há o sistema de jogo, o ataque combinado e a defesa (a recepção e o bloqueio).

Este trabalho seguirá as divisões sobre os fundamentos técnicos propostas acima, porém deve-se lembrar de que a divisão entre técnica e tática é apenas uma forma de facilitação do entendimento teórico de ambas, sendo elas indissociáveis num jogo esportivo.

\section{As posições e funções dos jogadores}

Num contato inicial com o esporte, os alunos devem conhecer e vivenciar todas as posições expandindo seu aprendizado e vivência de diversas habilidades, para, posteriormente, descobrirem e se especializarem naquela na qual possuem maiores êxitos e preferência.

No voleibol sentado, os jogadores ocupam as mesmas posições do convencional, já explicitadas anteriormente, podendo, segundo Macedo, ${ }^{7}$ assumir os papéis de atacante- o 
qual realiza a finalização visando marcar o ponto -, de levantador- quem executa o passe para o atacante finalizar -, de universal - o qual realiza as funções tanto de levantador quanto atacante - e de líbero - um jogador especializado em realizar as defesas.

\section{Fundamentos}

Como citado anteriormente, na iniciação e aprendizagem dos fundamentos, muito pouco se difere entre as duas modalidades de voleibol - o sentado e o convencional.

Como relevante diferença, em todos os fundamentos, o tronco passa a desempenhar um acentuado papel, ao assumir muitas das funções dos membros inferiores, como na transmissão de força para os membros superiores e também manutenção de equilíbrio corporal antes, durante e após a execução dos fundamentos. Também é exigido mais dos membros superiores, uma vez que eles irão realizar, além do deslocamento, os gestos, com grande exigência de força sem a ajuda do impulso que geralmente é realizado através dos saltos no voleibol convencional. ${ }^{4}$

Bizzocchi ${ }^{19}$ enfatiza que, no aprendizado do voleibol, a maior dificuldade encontrada pelos alunos será relacionada à correta execução dos fundamentos, pois estes são movimentos criados especialmente para essa modalidade não sendo realizados em outros esportes ou atividades físicas, exigindo paciência e compreensão do professor.

Por conseguinte, será através da execução dos seguintes fundamentos que se organizará e realizará o ataque e a defesa:

- O toque: pode ser utilizado com uma preparação para o ataque - no levantamento -, como uma defesa ou como o próprio ataque. Propõe-se nesse trabalho que, no voleibol sentado, a posição dos dedos e das mãos deve seguir a mesma orientação e posição do realizado no voleibol convencional- realizado acima da linha da cabeça, unindo os dedos indicadores e os polegares, adquirindo um formato semelhante ao triângulo, o qual deve permitir o perfeito encaixe da bola ao tocála apenas com os dedos, e não com a palma das mãos. 


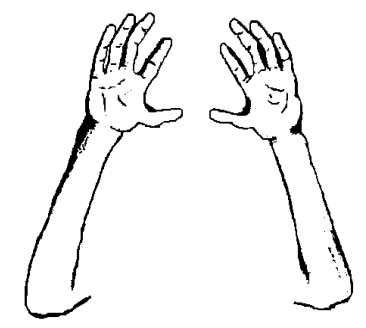

Figura 3: Posição das mãos no toque.

Fonte: Adaptado de Guilherme. ${ }^{20}$

Estando sentado, não haverá a típica realização do movimento de flexão dos membros inferiores, com atuação apenas do tronco e membros superiores. Como explicado por Darido e Souza Júnior, ${ }^{21}$ os cotovelos devem estar flexionados ao esperar a bola e, ao recebê-la, devem recuar e posteriormente se estender para lançá-la. O movimento realizado pelo pulso adquire respeitável função ao contribuir com o levantamento e direcionamento da bola, exigindo uma forte musculatura de antebraço e perfeita sincronização entre os movimentos dos dedos, pulsos e cotovelos.

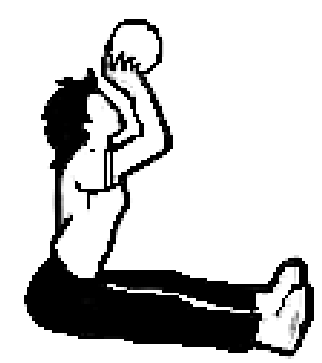

Figura 4: O toque no voleibol sentado. Fonte: Adaptado de Vute. ${ }^{4}$

O tronco deve se dirigir, com o auxílio dos braços, à proximidade da bola, proporcionando um posicionamento que facilite a realização do toque de forma equilibrada. Além disso, através de sua movimentação - se curvando e inclinando -, irá auxiliar na realização das três possibilidades de execução do toque: para frente, para trás ou lateralmente. Inicialmente é recomendada a exploração do toque de frente, incluindo posteriormente as outras direções, num trabalho conjunto coma postura e o equilíbrio corporal.22

- A Manchete: utilizada como recepção de um saque, passe ou defesa de um ataque, na manchete as mãos são colocadas uma sobre a outra unindo os dedos 
e aproximando os dois polegares, com os cotovelos estendidos, devendo haver o contato com a bola na parte interna dos antebraços. ${ }^{23}$

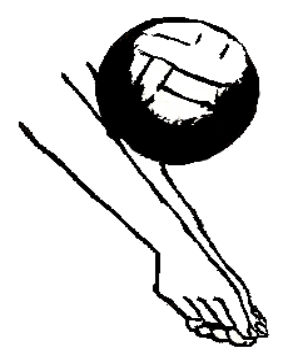

Figura 5: Posição dos braços na manchete.

Fonte: Adaptado de Guilherme. ${ }^{20}$

Os braços devem ser deixados soltos só construindo a posição de manchete imediatamente antes do movimento. Para ter o tempo necessário para a organização do movimento, o jogador deve visualizar o jogo prevendo e se posicionando no local adequado antes da chegada da bola. ${ }^{19}$ Propõe-se, neste trabalho que, no voleibol sentado, onde não há a movimentação dos membros inferiores, o tronco deve auxiliar a direcionar o movimento, possibilitando a colocação dos braços na direção correta na qual se deve enviar a bola.

Por conseguinte, os braços devem dirigir-se na direção da bola, podendo ser realizada de frente, de costas e na lateral.

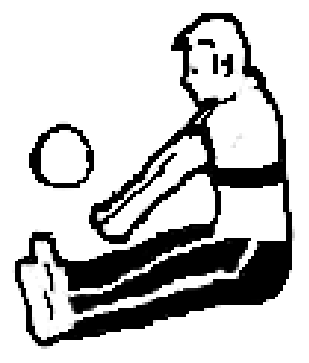

Figura 6: Manchete no voleibol sentado. Fonte: Adaptado de Vute. ${ }^{4}$

O professor deve estimular o aluno a interpretar cada situação de jogo para melhor agir, assim como a distinguir as posições dos membros inferiores mais confortáveis para a realização deste fundamento. ${ }^{4}$ 
- O Saque: É a forma pela qual se dá o início de cada jogada, podendo também ser uma oportunidade para a marcação de ponto. É realizado sempre pelo jogador da posição 1, após o sinal do árbitro, devendo a bola receber o golpe no ar, ultrapassar a rede por entre as antenas e atingir o lado da quadra adversária. ${ }^{23}$ Deve ser realizado com os glúteos atrás, podendo ser por toda a linha de fundo da quadra, porém os membros inferiores podem estar dentro desta. O saque pode ser por cima ou por baixo, dependo da escolha do jogador. ${ }^{4}$

Segundo Santini, ${ }^{23}$ o saque por baixo é recomendado para ser trabalhado inicialmente, no qual a bola deverá ficar posicionada sobre uma das mãos cujo braço estará à frente do corpo com o cotovelo estendido, enquanto o braço livre ficará estendido abaixo desta, e num movimento rápido, se deslocará para trás e posteriormente á frente golpeando a bola por baixo e lançando-a, como explicitado pela Figura 7.

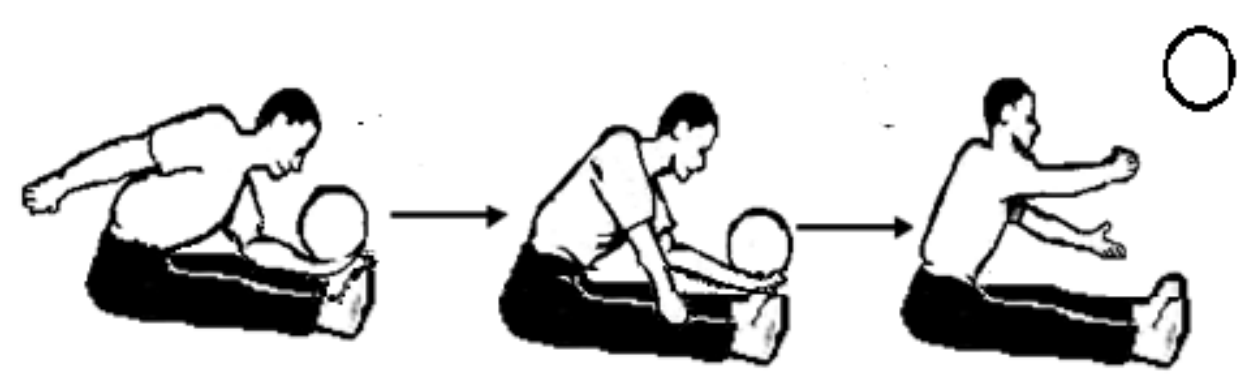

Figura 7: O saque por baixo.

Posteriormente, pode ser introduzido o saque por cima, demonstrado na Figura 8. Este possui várias maneiras de realização, porém, de uma forma geral, todos são fundamentados no lançamento da bola numa altura acima da cabeça por um braço estendido à frente do corpo e o posterior golpe nesta pelo outro braço que estará elevado para cima e para trás, vindo à frente para golpear e lançar a bola para a quadra adversária, exigindo maior coordenação e força. 

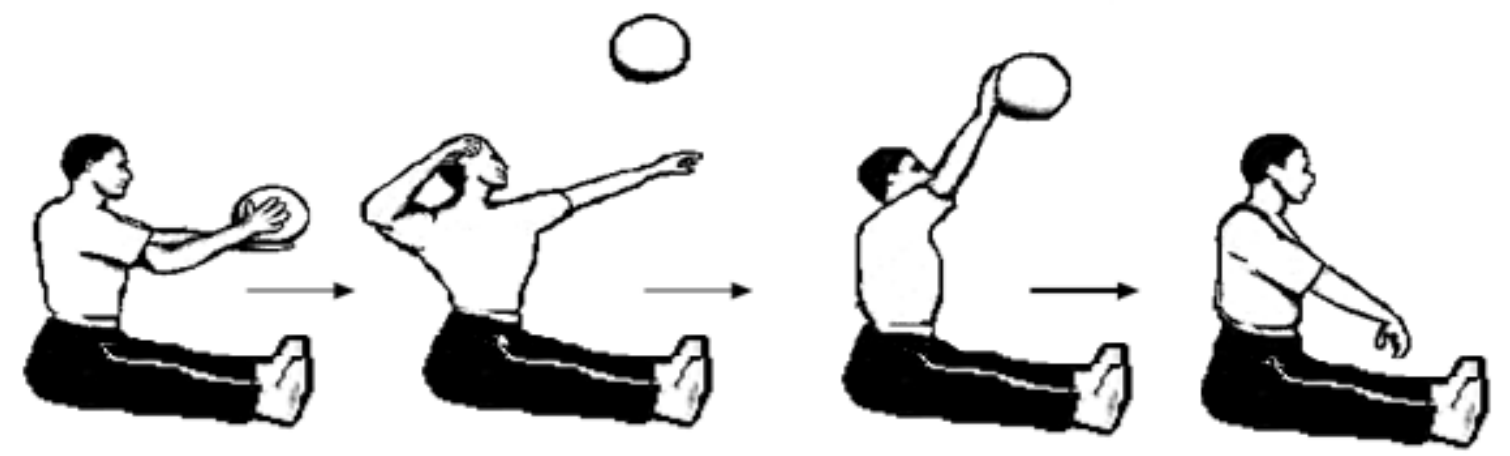

Figura 8: O saque por cima.

Conforme citado por Bizzocchi, ${ }^{19}$ no voleibol sentado, as possibilidades mais comuns para a realização do saque por cima são com rotação - no qual realiza-se a rotação da bola durante o seu deslocamento por meio de um movimento de flexão do punho durante o saque, golpeando a bola com a mão em forma de concha, exigindo maior equilíbrio do atleta -ou flutuante- neste a bola não apresenta rotação, pois a mão permanece firme e espalmada sem realizar flexão do pulso, o que proporciona maior estabilidade para o sacador.

O principal erro na execução do saque é a alteração da direção da bola - ao se dirigir para um lado não desejado -, o fato de a bola cair após lançá-la para cima antes de golpeá-la, e também o golpe na bola com as mãos fechadas. O aluno deve, por conseguinte, fixar sua atenção na bola, e manter os braços firmes e estendidos durante o saque e direcionados para um local da quadra adversária. Isso evitará que pequenas modificações de movimento dos braços no momento do saque alterem sua direção ou ocasionem erros. ${ }^{23}$ Conclui-se a necessidade de um preparo e fortalecimento dos membros superiores e equilíbrio do tronco. ${ }^{7}$

- A Cortada: É o movimento no qual o atacante golpeia a bola objetivando que ela ultrapasse a rede e toque no chão adversário, impossibilitando a defesa deste. Neste fundamento, o braço deverá ser elevado e estendido para trás da cabeça e posteriormente ser trazido para frente com velocidade e força. Após esse impulso, o braço golpeia a bola quando esta atinge uma posição um pouco acima e à frente da sua própria cabeça. O tronco deverá estender-se e posteriormente flexionar-se, aumentando a potência do ataque. ${ }^{20}$ Os jogadores devem tocar a bola no ponto 
mais alto possível, sendo para isso necessário um rápido deslocamento em direção à bola e de aproximação à rede exigindo, mais uma vez, agilidade e fortalecimento dos membros superiores. ${ }^{4}$

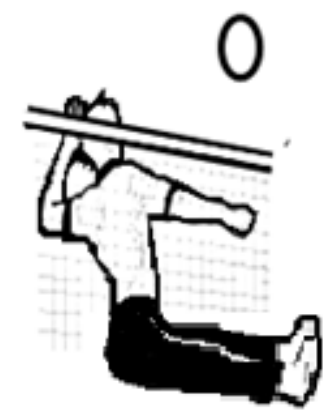

Figura 9: A cortada.

Segundo explica Guilherme, ${ }^{20}$ os atacantes devem aprender a analisar a atuação da equipe adversária, encontrando um lugar na quadra desta momentaneamente desprotegido ou mesmo direcionando a bola sobre um jogador que estiver despreparado no momento para uma possível defesa. Durante o ataque, os demais jogadores que não participam desse fundamento devem estar atentos proporcionando proteção a um possível retorno da bola para a sua quadra, ou seja, a um contra-ataque adversário. Não há um posicionamento prédefinido neste momento, contudo a participação do líbero e do levantador é imprescindível uma vez que o líbero é um jogador especializado na defesa e o levantador o jogador que armou o ataque direcionando a bola para um atacante específico sabendo, portanto, o local a ser protegido. ${ }^{19}$

- O Bloqueio: Consiste em impedir a passagem da bola quando o adversário pratica o ataque através da extensão dos braços e mãos paralelamente e acima da altura da rede, podendo ser uma forma de ataque ao direcionar a bola para o chão do adversário com a flexão dos pulsos. ${ }^{20}$ Pode ser feito por um, dois ou três jogadores, porém no voleibol sentado comumente realizam-se os bloqueios individual e duplo devido à menor velocidade de deslocamento. Ressalta-se a possibilidade de bloqueio contra o saque adversário. ${ }^{7}$ 


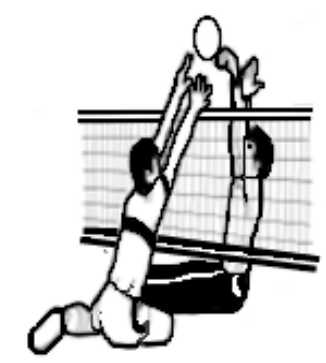

Figura 10: O bloqueio.

Fonte: Adaptado de Vute. ${ }^{4}$

- O Deslocamento: É o fundamento que mais se difere entre o voleibol convencional e o sentado, pois deverá ser feito através dos membros superiores, que conduzem o tronco até o local intencionado. Proporciona a base para todos os outros fundamentos e para isso, nas posições básicas de expectativa em que se espera o lançamento da bola, supõe-se que o jogador deverá estar com os membros superiores posicionados próximos ao chão com as mãos abertas e preparadas para conduzir um rápido deslocamento do tronco.

Como a base de todo o deslocamento estará nos membros superiores e tronco, torna-se indispensável o trabalho de fortalecimento e de equilíbrio destes. ${ }^{16}$ Deve-se, também, estimular a aprendizagem de diferentes formas de deslocamento, em variadas direções e velocidades, trabalhando com os alunos de forma individualizada uma vez que os diferentes tipos e níveis de deficiências irão influenciar diretamente na realização deste fundamento. ${ }^{4}$ Torna-se relevante ainda, segundo por Zerger, ${ }^{16}$ um trabalho de velocidade e de coordenação, já que muitos dos músculos utilizados para o deslocamento também são empregados na execução dos gestos técnicos dos fundamentos, exigindo do atleta rapidez para se deslocarem com os membros superiores, se posicionarem adequadamente e ainda coordenar as ações na realização do contado na bola, que deverá ser escolhido no momento de acordo com a situação de jogo.

As posições das mãos e pernas durante a movimentação ficam a escolha dos atletas.

\section{Ataque}

Com a finalidade de marcar ponto sobre o adversário, o ataque pode ser feito na forma de remate, passe ou largada. Segundo Macedo, ${ }^{7}$ no remate, o jogador golpeia a bola contra o 
chão da quadra adversária através da cortada; na largada, o atacante toca na bola com as pontas dos dedos, direcionando-a numa área da quadra adversária desprotegida; e por fim, no ataque através do passe a bola é enviada para o adversário por meio de um passe, podendo ser manchete ou toque.

O bloqueio também pode ser utilizado no ataque. Para isso, os mesmos movimentos de braços serão realizados como no bloqueio defensivo, porém os pulsos se flexionarão com o intuito de que a bola toque o próprio bloqueio e se dirijam para o solo adversário. ${ }^{20}$

O ensino do ataque deve ser feito com e sem defesa, ou seja, com a presença e a ausência de bloqueadores, proporcionando diferentes estímulos. Aos jogadores deve ser instigado o desenvolvimento da agilidade, do bom julgamento dos movimentos da bola, do conhecimento sobre as posições da quadra e as responsabilidades de cada jogador, além do respeito às regras e aos demais jogadores. Deve ser enfatizada, pelo professor, a necessidade de comunicação entre os participantes de uma equipe durante os jogos, pois a ausência desta é constante entre jogadores iniciantes, levando-os a muitos erros de leitura do jogo, sendo comum ir vários ou nenhum atleta para a recepção de uma bola adversária, por exemplo. ${ }^{4}$

Ainda segundo Vute, ${ }^{4}$ o voleibol sentado, assim como o convencional, permite três toques na bola antes de passá-la para a quadra adversária, sendo estes compostos pela recepção, levantamento e ataque, consecutivamente. Portanto, no ataque, o levantador também tem fundamental relevância, pois é ele quem o organiza.

O levantamento geralmente é realizado próximo à rede, tocando a bola acima da cabeça, lançando-a paralelamente à rede e próxima de um jogador atacante, numa altura que permita a aproximação deste. O movimento de levantamento depende, no voleibol sentado, do movimento de extensão dos braços que permitirá o lançamento da bola na direção e altura desejadas.

Ele pode ser feito por toque ou manchete, sendo preferível o uso do toque por este possibilitar maior controle sobre a direção da bola a ser lançada, e também por possuir a vantagem de ser realizado de forma mais rápida uma vez que o toque na bola ocorre Conexões: revista da Faculdade de Educação Física da UNICAMP, Campinas, v. 11, n. 2, p. 97-126, abr./jun. 2013.115 ISSN: 1983-9030 
enquanto esta ainda está numa altura sobre as cabeças, induzindo menor tempo para a organização do contra-ataque da equipe adversária. $\mathrm{O}$ levantamento pode ainda ser alto -ao levantar a bola a uma grande altura permitindo que o atacante tenha tempo suficiente para se deslocar até ela -; rápido - ao elevar a bola numa altura baixa, possibilitando que o ataque seja feito de forma mais rápida, surpreendendo o adversário -; e médio - ao lançar a bola numa altura média, proporcionando tempo para deslocamento e maior velocidade de ataque do que no levantamento "alto". ${ }^{19}$

No voleibol sentado, o levantador fica comumente posicionado na zona de ataque, facilitando a movimentação deste, já que seria desgastante o deslocamento deste por toda a quadra durante a partida, devido à condução sentada. Por conseguinte, quando a bola não estiver na zona de ataque para a realização do segundo toque e o levantador não tiver possibilidade de chegar a tempo, outro jogador da zona de defesa exercerá essa função momentaneamente. ${ }^{7}$

Durante o jogo, cabe ao levantador e ao atacante criarem situações de jogo imprevisíveis ao adversário. Quanto ao levantador, este deve ter boa análise de jogo para direcionar a bola para o atacante que possui melhores condições de marcar o ponto no momento. Ele deve, também, explorar as direções da rede e as possibilidades de atacantes, sempre observando o posicionamento tanto dos seus próprios atacantes quanto da defesa adversária. ${ }^{23}$

\section{Defesa}

Com o objetivo de proteger sua quadra e evitar o ponto adversário, na defesa inicialmente os jogadores devem permanecer na posição de expectativa, ou seja, uma postura que o possibilite desenvolver rápida reação frente às ações dos adversários, com os braços posicionados próximos ao solo e preparados para um possível rápido deslocamento. ${ }^{19}$

Para isso, segundo Zerger, ${ }^{16}$ um dos fundamentos mais importantes a ser trabalhado é o deslocamento, pois o jogador deve ser ágil, com mudanças rápidas de direção.

A defesa é realizada contra o saque ou o ataque do adversário, podendo, no voleibol sentado, ser feita através da recepção e também do bloqueio. ${ }^{3}$ 
As formas de bloqueio defensivo mais utilizado são o simples, com apenas um jogador, e o duplo, com dois jogares lado-a-lado. Há também o bloqueio triplo, com a participação de três jogadores, porém como citado por Macedo, ${ }^{7}$ este não é muito empregado no voleibol sentado devido á dificuldade de deslocamento de três jogadores concomitantemente.

Um ponto importante a ser desenvolvido na defesa é a forma de recepção, que pode ser através do toque ou da manchete. No voleibol convencional é estimulado o uso da manchete uma vez que o toque pode gerar maior índice de erros,contudo, no voleibol sentado, os jogadores utilizam principalmente o toque devido à maior facilidade de empregar este de acordo com as características de posicionamento e deslocamento da modalidade adaptada. ${ }^{7}$

Há também a possibilidade dos defensores se organizarem na quadra de diferentes maneiras objetivando facilitar a defesa, sendo duas as formas mais utilizadas: a recepção em "W" e a em "meia-lua". Rodrigues ${ }^{24}$ cita a recepção "W" como a mais aconselhável para início do treinamento, sendo esta um tipo de recepção que envolve cinco jogadores, excluindo apenas o levantador, numa distribuição na zona de defesa da quadra de uma forma que remete à letra "w". Nesta, os jogadores das posições 5 e 1 estarão próximos entre si e da linha de fundo de quadra, os jogadores das posições 4 e 2 estarão próximos da linha de 2 metros e da sua respectiva linha lateral, e por último, o jogador da posição 6 deverá ocupar a posição central entre os demais. Este mesmo autor define ainda a recepção em "meia lua" como quando os jogadores que realizam a defesa se dispõem na quadra após a linha dos 2 metros formando o desenho de uma meia lua ao se distribuírem entre as linhas laterais e de fundo da quadra. Esses dois sistemas de recepção podem ser observados na Figura11. Além destes, há também a possibilidade de uma defesa composta por três jogadores, na qual geralmente estes adquirem uma posição de linha reta no fundo da quadra. 

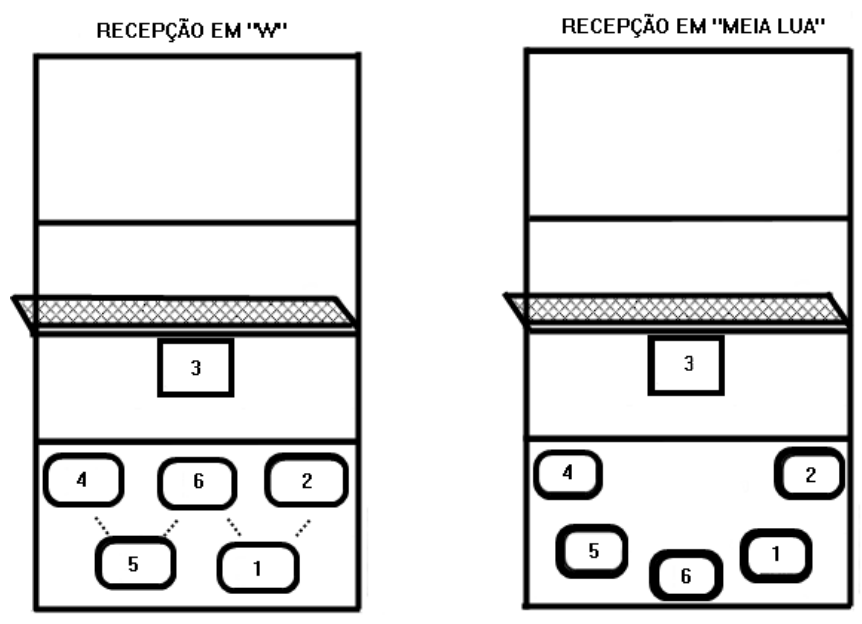

Figura 11: Sistemas de recepção.

Legenda: $\square$ Levantador (não participa da recepção).

Jogadores que participam da recepção.

O líbero possui papel relevante e necessita de destaque especial nesse fundamento, uma vez que é jogador especializado e unicamente designado para as funções de recepção e defesa. De acordo com as regras, esse jogador é proibido de ser capitão da equipe, de sacar e de efetuar um ataque. Dentro da quadra, ocupa principalmente a zona 5 ou 6 , locais nos quais geralmente são destinadas as maiores quantidades de bolas oriundas do ataque adversário. $^{25}$

Deve-se ressaltar que a forma de defesa a ser empregado depende do tipo e da maneira como é realizado o ataque pelo adversário. Além disso, o ensino da defesa deve ter prioridade entre atletas iniciantes, pois só após conseguir defender a bola adversária, que o time terá a oportunidade de atacar, além de considerar que constantes erros de defesa e pontuações do time oponente podem desestimular o time, causando frustrações e falta de interesse no jogo. ${ }^{4}$

\section{Sistemas de jogo}

No sistema de jogo há a delimitação do posicionamento dos jogadores, objetivando distribuí-los na quadra de forma que possibilite maiores chances de defesa e de ataque. Conforme pode ser visualizado na Figura 12, quando uma equipe não estiver com a posse de bola e marcar um ponto, ela deverá realizar o rodízio na primeira vez em que sacar. Este giro deverá ser feito no sentido horário, com a transferência do jogador que estiver na posição 6 para a 5, o jogador da posição 5 para a 4 e assim por diante, conforme a Conexões: revista da Faculdade de Educação Física da UNICAMP, Campinas, v. 11, n. 2, p. 97-126, abr./jun. 2013.118 ISSN: 1983-9030 
definição das posições já relatadas anteriormente. O jogador que, no final do rodízio, ocupar a posição 1 , realizará o saque. ${ }^{3}$

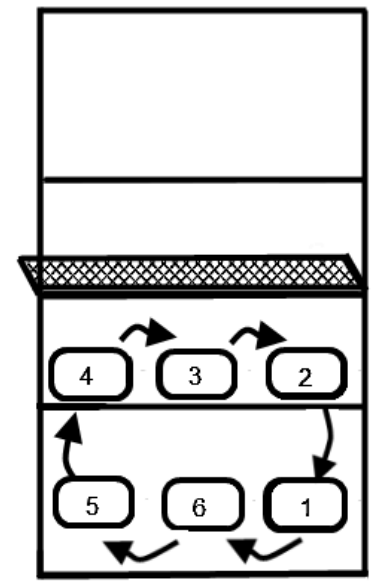

Figura 12: O sistema de rodízio.

Os sistemas de jogo aplicados são os mesmos do voleibol convencional.

$\mathrm{Na}$ tática ofensiva são mais utilizados os sistemas $4 \times 2,5 \times 1,6 \times 0$ e $3 \times 3$, enquanto na defensiva o $3 \times 2 \times 1,3 \times 1 \times 2$ e $3 \times 0 \times 3 .^{18}$

Sobre a tática ofensiva, o sistema de jogo mais apropriado para a iniciação da prática é o6 x 0 , visto que neste todos poderão atuar em nas diferentes posições do jogo. Dessa forma, ele contribuirá para a ampliação do desenvolvimento das habilidades de cada jogador, oportunizando que cada um, através da vivência, adquira diferentes habilidades motoras, e só posteriormente, inicie a especialização em uma posição definitiva na qual preferir e obtiver melhor desempenho. Neste sistema os jogadores, organizados nas posições numeradas de 1 a 6 , ocuparão a função da posição na qual estiver no momento, sendo o levantador quem ocupar a posição 3. Após o rodízio, trocarão de lugares e desempenharão a função da nova posição. ${ }^{8}$

Posteriormente, o profissional de educação física poderá inserir os outros sistemas de jogo, como o sistema 4 x 2. Utilizado no início do processo de especialização, este inclui quatro jogadores na função de atacante e outros dois na função de levantadores. Os jogadores podem ser distribuídos na quadra de forma que os dois levantadores ocupem posições opostas entre si, por exemplo, um levantador ocupará a posição 4 enquanto o outro ficará 
na posição 1. Há, por conseguinte, uma organização para que sempre um levantador fique na rede, podendo ser aplicado com ou sem infiltração- deslocamento do levantador que estiver na zona de defesa, após o saque, na zona de ataque. Já o sistema5 x 1, com cinco atacantes e um levantador, é o mais explorado por equipes de alto nível, uma vez que há apenas um levantador para realizar a distribuição da bola para todos os demais, exigindo maior preparo deste, mesmo que, quando este não tiver tempo suficiente para deslocar-se até a bola um outro jogador possa assumir essa função. ${ }^{21}$

Há ainda o sistema ofensivo $3 \times 3$, com três levantadores e três atacantes, que ficam intercalados, podendo cada atacante atuar com um levantador específico. ${ }^{7}$

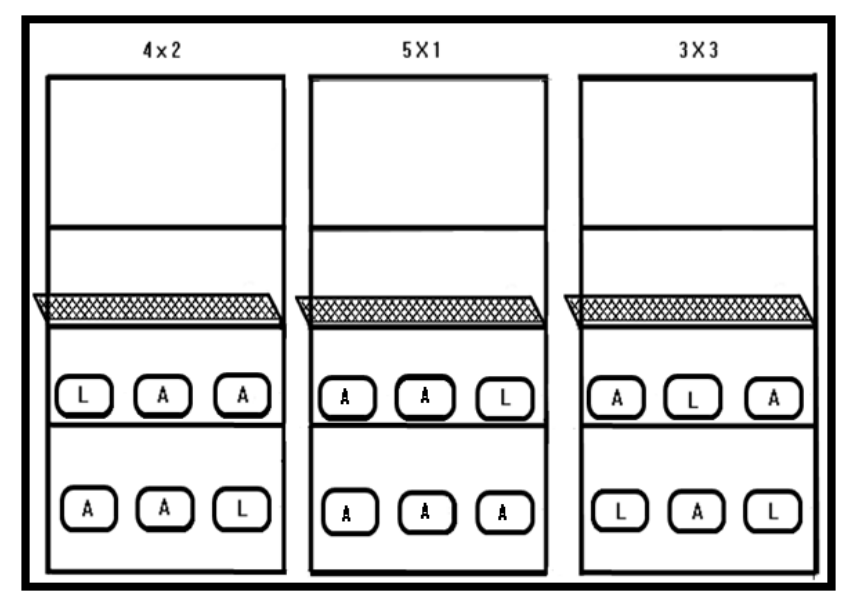

Figura 13: Os sistemas ofensivos mais utilizados no voleibol sentado. Legenda : A: Atacante. L: Levantador.

Quanto à tática defensiva, são três os principais sistemas de jogo - o 3 x 2 x 1,3 x 1 x 2 e 3 x 0 × 3 . No sistema $3 \times 2 \times 1$, os três jogadores da linha de frente ficarão alinhados próximos à rede, os jogadores das posições 5 e 1 ficarão alinhados na zona de defesa próximos à linha dos 2 metros e o jogador da posição 6 se aproximará da linha do fundo de quadra. No sistema $3 \times 1 \times 2$ exige que os três jogadores da linha de frente fiquem alinhados próximos á rede, enquanto na zona de defesa o jogador da posição 6 ficará mais próximo da linha dos 2 metros e do bloqueio e os defensores das posições 5 e 1 ficarão alinhados próximos à linha de fundo de quadra. Por fim, no sistema 3 x 0 x 3, os jogadores da defesa e do ataque ficarão posicionados a uma mesma distância da linha lateral, formando duas linhas, uma no ataque e outra na de defesa. ${ }^{24}$ 

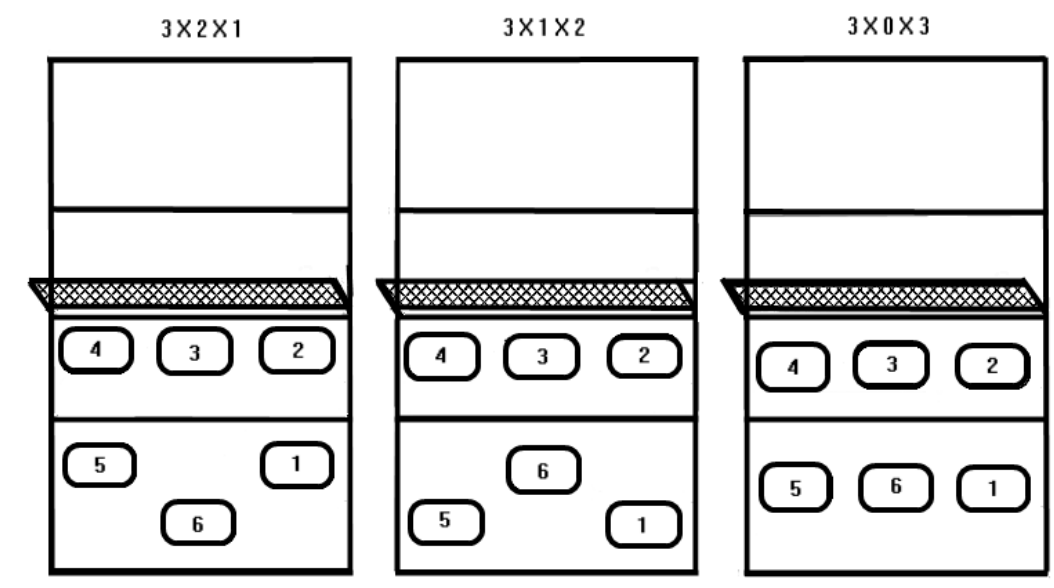

Figura 14: Os sistemas defensivos mais utilizados no voleibol sentado.

Observa-se que, após esse primeiro momento de organização, a formação da defesa irá sofrer transformações adquirindo novos posicionamentos de acordo com o jogo de ataque feito pela equipe adversária e pelo tipo de bloqueio executado pela própria equipe.

\section{Recursos}

Para Bizzocchi, ${ }^{19}$ os recursos são gestos e movimentos que podem ser aplicados durante o jogo quando é dificultoso ou impossível de ser utilizado algum dos fundamentos acima descritos. Podem ser divididos em recursos de ataque (utilizados como uma forma de ataque são denominados de explorada - na qual o atacante induz a bola a tocar no bloqueio adversário e posteriormente dirigir-se para fora da quadra de ambos -, largada - quando o atacante toca na bola levemente, colocando-a num local da quadra adversária que estiver desprotegida -, empurrada -no momento em que o atacante atua empurrando a bola para que ela fique entre a rede e o bloqueio adversário, desestruturando a defesa deste - e meiaforça - na qual o atacante diminui a quantidade de força empregada para golpear a bola no momento do ataque, surpreendendo a defesa), recursos de levantador (composto pela largada de segunda -na qual o levantador realiza, no segundo toque da bola, o mesmo movimento do recurso de largada do ataque -, ataque de segunda-quando o levantador, durante o segundo toque, ao invés de conduzir a bola para o atacante, ele mesmo golpeia a bola com força atacando o adversário - e simulação de ataque - na qual o levantador simula a realização do ataque de segunda, anteriormente mencionado, mas realiza um levantamento normal para um atacante), recursos de defesa (desenvolvidos com o objetivo de defender sua quadra, podem ocorrer através da defesa com as mãos abertas acima da cabeça, com apenas uma das mãos fechada, com apenas um dos braços, ou ainda através Conexões: revista da Faculdade de Educação Física da UNICAMP, Campinas, v. 11, n. 2, p. 97-126, abr./jun. 2013. 121 ISSN: 1983-9030 
do "abafa" - quando o jogador estende suas mãos no chão para que a bola toque nesta ao invés do solo- e do "tapinha" - no qual atleta joga a bola para cima com o dorso da mão), e recursos de bloqueio (os quais compreendem os mecanismos "Evitando exploradas de bloqueio pelo atacante" - ao interpretar que o adversário irá aproveitar seu bloqueio para realizar o recurso de explorada do ataque, os bloqueadores retiram as mãos da direção da bola durante o bloqueio, para que ela não atinja suas mãos e vá para fora da quadra -, "Disputa de bloqueio x bloqueio" - quando ambos os jogadores adversários realizam o bloqueio deixando a bola presa sobre a rede, objetivando evitar tocar a bola antes que o adversário, pois quem tocar na bola depois do outro ficará com esta em seu domínio por último podendo conduzi-la à quadra adversária - e "Puxada" - na qual o bloqueador posiciona seus braços em um local da rede, e no momento do ataque adversário, os desloca para o local do ataque).

\section{CONSIDERAÇÕES FINAIS}

Desde o início do esporte adaptado, Dr. Guttmann conseguiu reverter a estatística de sobreviventes de lesados medulares de 1:10 (sobrevivente: mortes) em 1940 pra 9:10 em 1950 por meio do uso do esporte como fonte de reabilitação. ${ }^{3}$ A partir dessa origem terapêutica, o esporte adaptado consolidou-se como uma prática competitiva de alto rendimento.

Nesse contexto, houve grandiosa ascensão do voleibol sentado nos últimos anos, trazendo benefícios com sua prática para as pessoas em condição de deficiência, como ao melhorar a força dos membros superiores e do tronco, a coordenação motora e as aptidões cardiorrespiratórias, além dos benefícios psicossociais. ${ }^{26}$

Com características e regras muito semelhantes ao convencional, o voleibol sentado pode ter sua prática iniciada com procedimentos muito parecidos, com apenas os trabalhos de deslocamento sendo desenvolvidos de maneira claramente específica. Como consequência, apesar da ínfima quantidade de literatura dedicada à prática de voleibol sentado, é possível esta se desenvolver através da adaptação do treino do voleibol comum, apresentando então, uma possibilidade de trabalho aos profissionais de educação física. 
Com a precariedade de literatura sobre o assunto, tornam-se necessárias pesquisas sobre essa modalidade adaptada, auxiliando o desenvolvimento, a sustentação, a atualização e propagação do voleibol sentado. Sugere-se que posteriores pesquisas sejam realizadas explorando os diferentes aspectos envolvidos na sua prática, como as dimensões técnicotáticas mais eficientes e condicionamento específico para os atletas desta modalidade.

Dessa forma, mais estudos proporcionarão maior fundamentação para a massificação dessa prática e a elevação na qualidade e eficiência, no âmbito do treinamento, dos praticantes ou atletas já existentes.

\section{REFERÊNCIAS}

1WINNICK, J. P. Educação física e esportes adaptados. 3. ed. Barueri: Manole, 2004. $552 \mathrm{p}$.

${ }^{2}$ COMITE PARAOLÍMPICO BRASILEIRO. (CPB). Disponível em: <http://www.cpb.org.br>. Acesso em: 12 nov. 2009.

${ }^{3}$ WORLD ORGANIZATION VOLLEYBALL FOR DISABLED. (WOVD). Disponível em: 〈http://www.wovd.info>. Acesso em: 20 jun. 2010.

${ }^{4}$ VUTE, R. Teaching and coaching volleyball for the disabled: foundation course handbook. $2^{\text {nd }}$ ed. Ljubljana: Faculty of Education, 2009. 58p.

${ }^{5}$ VUTE, R. Self-perception of national team coaches in volleyball for the disabled. Gymnica, Olomouc, v. 35, n.1, p. 69-77, 2005. Disponível em: < http://www.gymnica2.upol.cz/gymnica-35_1.pdf\#page=69>. Acesso em: 16 mar. 2010.

${ }^{6}$ MUSTAFINS, P. et al. Rate and type of participation limiting health disorders in sitting volleyball players (Health disorders in Sitting Volleyball players). Papers on Anthropology, v. 13, p. 233-247, 2008. 
${ }^{7}$ MACEDO, C. D. Análise das características do jogo de voleibol sentado a partir da recepção do serviço. 2005. 139 f. Dissertação (Mestrado em Ciência do Desporto) Faculdade de Ciência do Desporto e Educação Física, Universidade do Porto, Porto, 2005.

${ }^{8}$ ALMEIDA, V. A. Estrutura interna do jogo de voleibol: estudo comparativo entre o nível de eficácia no ataque dos jogadores zona 2 e zona 4. 2009. 45 f. Trabalho de Conclusão de Curso (Licenciado em Educação Física) - Faculdade de Ciências do Desporto e Educação Física, Universidade de Coimbra, Coimbra, 2009.

${ }^{9}$ ARAÚJO, P. F. Desporto adaptado no Brasil: origem, institucionalização e atualidade. Brasília: INDESP, 1998. 147p.

${ }^{10}$ BRITTAIN, I. The paralympic games explained. New York: Routledge, 2010. 172p.

11TAJNIK, M. Diferenças entre o voleibol e o voleibol sentado. 2009. 69f. Tese (Educação Física Especial) - Faculdade de Desporto , Universidade de LJUBLJANI, LJUBLJANI, 2009. (tradução nossa).

${ }^{12}$ GIOIA, F. M.; SILVA, P. F. R.; PEREIRA, E. G. B. Voleibol sentado: uma reflexão bibliográfica e histórica. Revista Digital Lecturas: Educación Fisica y Deportes, Buenos Aires, v. 13, n. 125, out. 2008. Disponível em: 〈http://www.efdeportes.com.ar〉. Acesso em 20 set. 2009.

${ }^{13}$ DEPAUW, K. P.; GAVRON, S. J. Disability and sport. Champaign: Human Kinetics, 1995. $298 \mathrm{p}$.

${ }^{14}$ SHERRILL, C. Leadership training in adapted physical education. Champaign: Human Kinetics, 1988. 512p.

${ }^{15}$ GARGANTA, J. Para uma teoria dos jogos desportivos coletivos. In: GRAÇA, A.; OLIVEIRA, J. (Ed.). O ensino dos jogos desportivos. 2. ed. Porto: Universidade do Porto, 1995. 
${ }^{16}$ ZERGER, M. A study of movement in sitting-volleyball. 2008. 52 f. Dissertação (Mestrado em Cinesiologia e Estudos de Saúde) - Jackson College of Graduate Studies, University of Central Oklahoma, Oklahoma, 2008.

${ }^{17}$ TAVARES, F. O processamento da informação nos jogos desportivos. In: GRAÇA, A.; OLIVEIRA, J. (Ed.). O ensino dos jogos desportivos. 2. ed. Porto: Universidade do Porto, 1995.

${ }^{18}$ PIROLO, A. L.; PIROLO, D. O voleibol e sua metodologia. In: SEMANA DA EDUCAÇÃO FÍSICA, 3., 1998, Maringá. Trabalho de revisão de literatura. Maringá: Universidade Estadual de Maringá, 1998. Disponível em: < http://www.bwnet.com.br/ affp/links_arq/mv_uem_1998.pdf>. Acesso em: 06 maio 2010.

${ }^{19}$ BIZZOCCHI, C. O voleibol de alto nível: da iniciação a competição. 3. ed. Barueri: Manole, 2008. 328p.

${ }^{20}$ GUILHERME, A.Voleibol a beira da quadra: conhecimentos úteis aos dirigentes, treinadores e atletas. São Paulo: Gráfica Aimorés, 1975. 36p.

${ }^{21}$ DARIDO, S. C.; SOUZA JÚNIOR, O. M. de. Para ensinar educação física: possibilidades de intervenção na escola. Campinas: Papirus, 2007. 349p.

22BOJIKIAN, J. C. M. Ensinando voleibol. 2. ed. São Paulo: Phorte, 2003. 183p.

${ }^{23}$ SANTINI, J. Voleibol escolar: da iniciação ao treinamento. Canoas: Ed. da ULBRA, 2007. 148p.

${ }^{24}$ RODRIGUES, L. Voleibol: o sistema de jogo. Revista Horizonte, v. 6, n. 36, p. $194-$ 197, mar./abr. 1990.

${ }^{25}$ LUCIANO, S. D. Importância do jogador libero nas acções ofensivas no jogo de voleibol: estudo da prestação do jogador libero em equipas participantes da Liga Mundial 
de Voleibol 2004/2005. 2006. 123 f. Dissertação (Mestrado em Ciências do Desporto) Faculdade de Ciência do Desporto e Educação Física, Universidade do Porto, Porto, 2006.

${ }^{26}$ MOLIK, B.; KOSMOL, A.; SKUCAS, K. Sport: specific and general sporting physical fitness of sitting volleyball athletes. Physiotheraphy, Warszawa, v. 4, n. 16, p. 68-75, 2008. Disponível em: <http://journals.indexcopernicus.com/abstracted.php?icid=882236>. Acesso em: 14 ago. 2010.

Recebido em: 27 mar. 2013 Aceito em: 30 maio 2013

Contato: Camila Lopes Carvalho camilalopes.c@hotmail.com 